\title{
Response of Aspergillus and Rhizopus species to the Toxicity of Dispersants
}

\author{
Williams, Janet Olufunmilayo*, Chibuike, Princess Mebom and \\ Giadom, Barinaale Happiness
}

\author{
Department of Microbiology, Rivers State University, Port Harcourt, Nigeria \\ *Corresponding author
}

\begin{tabular}{|l|}
\hline Ke y w o r d s \\
Oil spill dispersant, \\
OSD/SEACARE, \\
OSD/LT, \\
Aspergillus and \\
Rhizopus species
\end{tabular}

\section{A B S T R A C T}

The aim of this study was to assess the toxicity of dispersants (OSD/SEACARE and OSD/LT) with different concentrations on the growth of Aspergillus and Rhizopus species in fresh water (Ocdee River) in KegbaraDereGokana Local Government Area, Rivers State. The Fresh water sample was collected by submerging 10liters of jerry Can (sterile) into a depth of $30 \mathrm{~cm}$ in K-Dere River in Gokana Local Government Area, Rivers State. The samples were transported to the laboratory in sterile containers packed in coolers in an ice pack for analyses within six hours of collection. Oil spill dispersants; OSD/SEACARE and OSD/LT were obtained from Barker and Hughes Nig. Ltd (formally Mil Park Nigeria Limited) in Port Harcourt Rivers State. The toxicity testing was done for the period of days at room temperature. Standard microbiological techniques were used; toxicity testing was prepared by setting up conical flask aseptically covered with cotton wool. For each dispersant (toxicant), the test was carried out in five (5) separate conical flasks containing appropriately sterile habitat water (freshwater). In each of the conical flask, four toxicant concentrations $(\%) ; 10,25,50$, and 75 were added separately. These concentrations were obtained by aseptically transferring $10,25,50$ and $75 \mathrm{ml}$ of the dispersant into $90,75,50$, and $25 \mathrm{ml}$ of sterile freshwater. The control contained the water sample (habitat water) and the organism without toxicant. One millilitre $(1 \mathrm{ml})$ of the test organism was added to each toxicant concentration in test tubes containing $(10,25,50,75 \%$ and control respectively). Aliquot $(0.1 \mathrm{ml})$ from each concentration was then plated out using spread plate technique on Sabouraud Dextrose Agar immediately after zero (0) hour inoculation was done, inoculation and spreading continued after 4, 8, 12 and 24 hours for short time toxicity (Acute) while for long time (Chronic) inoculation was from 168 (7days), 336 (14days), 504 (21days) and 672 (28days) hours respectively and the plates were incubated for 72 hours at $28 \pm 2^{\circ} \mathrm{C}$. After incubation, the total viable count on each plate was taken and converted to $\log _{10}$. This process was repeated for the two test organisms and two dispersants separately giving a total number of twenty (20) experimental set-ups. The result obtained showed that the two dispersants employed in this study pose lethal threats to the biological population of the aquatic environment and tend to seriously alter the overall stability of the river ecosystem $\left[{ }^{2}\right]$ as observed with the response of Aspergillus and Rhizopus species to the toxicity of dispersant with respect to other forms of life. However, the result of the percentage (\%) log survival count showed that Aspergillus and Rhizopus species are quite tolerant to the toxicants at some concentrations and exposure times as seen in table 4.4 and 4.5 which showed that the organisms had reasonable growth at $10 \%$ and $25 \%$ concentrations of the toxicants at $0,4,8$ hours, and to some extent, 12 and 24hours. The sensitivity of the fungi; Aspergillus and Rhizopus species to the toxicity of different toxicants (OSD/SEACARE AND OSD/LT) with the fresh water sample decreased in the following order (noting the lower lethal concentration (Lc50), the more toxic the toxicant); Aspergillus in OSD/SEACARE (56.15\%), Aspergillus in OSD/LT (58.81\%) and Rhizopusin OSD/SEACARE (58.05\%), Rhizopusin OSD/LT (58.40\%). The study revealed that the fungal species; Aspergillus and Rhizopus species responded differently to different concentrations of the two toxicants from time to time and the response of the organisms due to the presence of the toxicant may alter or affect the process of decomposition, mineralization and nutrient generation which will in turn disturb the nature of the ecosystem and biogeochemical cycle. Furthermore, the study also revealed that dispersants contain some chemical components that can be very hazardous to life, reducing productivity and promoting death of not just the aquatic forms of life (both the micro and macro flora) but also higher forms of life such as humans and other mammals that make use of them as source of food and other means of survival. 


\section{Introduction}

Dispersants are substances that contain surfactants, solvents and chemicals that break up oil slick into small droplets (Fingas et al., 1995). Dispersants have surfactants; which are surface active agents with molecules comprised of groups of opposing charges and solubility that is surfactants have both hydrophilic and lipophilic properties. Surfactants that are synthetic can be negatively charged, positively charged, nonnegatively charged, or amphoteric however, negatively or non-negatively surfactants are the only crude oil dispersants that are utilised.

Surfactants often include mixtures of other chemical agents such as solvents which improve the dispersing efficiency of the surfactant (Bennett, 2010).

They are a class of chemical compounds used in the control of oil spilled in aquatic environments (NRC, 2005). A Chemical dispersant which is biodegradable or the measure of the amount of oxygen required in degrading the chemical added to the oil polluted water is an important environmental distress when using dispersants. Oxygen can be of high demand when using dispersants, therefore, its use on spills in polluted coastal bays or inland waters with limited circulation could reduce or lower the dissolved oxygen resources, therefore causing harm to biological communities in such water (Hamdan and Fulmer, 2011).

\section{Materials and Methods}

\section{Place of study}

The Fresh water sample was collected by submerging 10liters of jerry Can (sterile) into 30 centimetre depth in the K-Dere river, Gokana L.G.A Rivers State. The samples were transported to the laboratory in sterile containers packed in coolers in an ice pack for analyses within six hours of collection. Oil spill dispersants; OSD/SEACARE and OSD/LT were obtained from Barker and Hughes Nig. Ltd (formally Mil Park Nigeria Limited) Port Harcourt in Rivers State.

\section{Microbiological analysis}

\section{Serial dilution}

One millilitre $(1 \mathrm{ml})$ each of the water sample was transferred into $9 \mathrm{ml}$ of normal saline diluent. After thorough shaking, further tenfold (v/v) serial dilutions were made by transferring $1 \mathrm{ml}$ of the original solution to freshly prepared normal saline diluents to a range of $10^{-4}$ dilutions (Prescott et al., 2005).

\section{Inoculation and incubation}

Aliquots $(0.1 \mathrm{ml})$ of the dilutions was inoculated to surface dried Nutrient agar in duplicates for enumeration of total heterotrophic bacterial population, and Sabouraud Dextrose Agar (SDA) plates containing antibiotic (Tetracycline) for total heterotrophic fungal count. The plates were incubated at $37^{\circ} \mathrm{C}$ for 24 hours except the SDA plates which were incubated at $28^{\circ} \mathrm{C}$ for three (3) days.

\section{Enumeration and isolation of pure culture}

\section{Total heterotrophic bacteria}

Total Heterotrophic Bacteria was enumerated as described by Okerentugba and Ezeronye (2003). Bacterial Colonies that appeared on Nutrient agar plates after 24 hours of incubation at $37^{\circ} \mathrm{C}$ were counted and the mean expressed as cfu/ml for the respective samples [2]. The colony forming unit per gram of sample was calculated using the formula below; 


\section{$\mathrm{CFU} / \mathrm{ml}=\frac{\text { number of colonies }}{\text { Dilution } \mathrm{x} \text { volume plated }}$}

Equation 1

The discrete colonies were sub cultured on fresh Nutrient agar plates in order to isolate pure culture cultures.

\section{Total heterotrophic fungi count}

This was determined using the Sabouraud Dextrose Agar plates containing antibiotic (Tetracycline) to inhibit bacterial growth, in duplicate, spread evenly using flamed bent rod and incubated at $28^{\circ} \mathrm{C}$ for 3days (Williams and Dimbu, 2015). After which the colonies were counted and the average of the count recorded accordingly.

\section{Identification of the test fungal isolates}

The fungal isolates were identified based on cultural and morphological characteristics such as colony growth pattern, conidial morphology, and pigmentation. The technique described by (Cheesbrough, 2006) was also adopted for the identification of the isolated fungi using cotton blue in lacto phenol stain. This was done by placing a drop of the stain on clean slide with the aid of a mounting needle, where a small portion of the aerial mycelia from the representative fungal cultures was removed and placed in a drop of lacto phenol. The mycelium was well spread on the slide with a needle.

A cover slip was gently placed with little pressure to eliminate air bubbles. The slide was then mounted and viewed under the light microscope with $\times 10$ and $\times 40$ objective lenses. The morphological characteristics and appearance of the fungal isolates seen were identified in accordance with standard scheme for identification of fungi as adopted by Williams and Dimbu (2015).

\section{Standardization of inocula for toxicity testing}

Pure cultures of each isolate was inoculated into respective Sabouraud Dextrose Broth and incubated at $37^{\circ} \mathrm{C}$ for 3 days. Surface viable counts were carried out in accordance with the method reported by Williams and Ogolo, 2017. Turbidity of the microbial suspensions was adjusted to match that of $0.5 \mathrm{McF}$ arland standards $\left(10^{5} \mathrm{CFU} / \mathrm{ml}\right)$ by making a dilution of 1:100 in sterile broth.

\section{Toxicity test procedure}

The toxicants were prepared by setting up conical flask aseptically covered with cotton wool. The test was carried out in five (5) separate conical flasks containing appropriately sterile habitat water (freshwater). In each conical flask, the four toxicant concentrations $(\%) ; 10,25,50$, and 75 of the dispersant were added separately. These concentrations were obtained by aseptically transferring $10,25,50$ and $75 \mathrm{ml}$ of the dispersant into 90, 75, 50, and $25 \mathrm{ml}$ of sterile freshwater.

The control contains the water sample (habitat water) and the organism without the toxicant. One millilitre $(1 \mathrm{ml})$ of the test organism was added to each toxicant concentration in test tubes containing $(10,25,50,75 \%$ and control respectively). Aliquot $(0.1 \mathrm{ml})$ from each concentration was then plated out using spread plate technique on Sabouraud Dextrose Agar immediately after inoculation zero (0) hour, inoculation and spreading continue after 4, 8, 12 and 24hours for short time toxicity (Acute) while for long time (Chronic) inoculation were from 168 (7days), 336 (14days), 504 (21days) and 672 (28days) hours respectively and was incubated for 72 hours at $28 \pm 2^{\circ} \mathrm{C}$ After incubation, the total viable count on the plate were taken and converted to $\log _{10}\left[{ }^{16}\right]$. This process was 
repeated for the two test organisms and two dispersants separately giving a total number of twenty (20) experimental set-ups.

\section{Determination of percentage log survival of the test organisms}

The percentage log survival of the test organisms were determined by dividing logarithmic count of the toxicant concentration, by the logarithmic count of the control and multiplying by 100 .

Percentage $(\%)$ logarithmic survival $=\underline{\log }$ $\underline{\mathrm{C}} \times 100$

Log c .......Equation 2

Where;

$\log \mathbf{C}=\log$ arithmic count of the toxicant, $\log c=\log$ arithmic count of the control

\section{Percentage log mortality}

The Percentage (\%) log mortality of the test organisms exposed to the toxicant were determined by subtracting the one hundred from the value of the percentage log survival

Percentage $(\%)=100-\% \log$ survival ..Equation 3

\section{Median lethal concentration $\left(\mathbf{L C}_{50}\right)$}

The median lethal concentration of the two dispersants on the test organisms in aquatic ecosystems were determined by subtracting the value of the highest concentration used $(75 \%)$ from the sum of concentration difference, multiplied by the mean percentage mortality and divided by the control (100).

$\mathrm{LC}_{50}=$

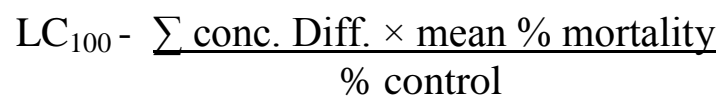

Equation 4

\section{Results and Discussion}

The results of total heterotrophic bacterial and fungal counts obtained from the freshwater sample are presented in figure 4.1 below.

Table.1 Average log count of Aspergillus species exposed to dispersant (OSD/LT) for 28 days

\begin{tabular}{|l|l|l|l|l|r|r|r|r|r|}
\hline Conc./Duration & $\mathbf{0}$ & $\mathbf{4}$ & $\mathbf{8}$ & $\mathbf{1 2}$ & $\mathbf{2 4}$ (hours) & $\mathbf{7}$ & $\mathbf{1 4}$ & $\mathbf{2 1}$ & $\mathbf{2 8}$ (days) \\
\hline $\mathbf{O} \%$ & 1.95 & 2.01 & 2.06 & 2.12 & 2.17 & 2.18 & 2.20 & 2.22 & 2.23 \\
\hline $\mathbf{1 0 \%}$ & 1.93 & 1.92 & 1.90 & 1.89 & 1.88 & 1.85 & 1.84 & 1.80 & 1.69 \\
\hline $\mathbf{2 5 \%}$ & 1.86 & 1.87 & 1.80 & 1.78 & 1.74 & 1.69 & 1.62 & 1.55 & 1.49 \\
\hline $\mathbf{5 0 \%}$ & 1.83 & 1.78 & 1.74 & 1.71 & 1.69 & 1.61 & 1.54 & 1.47 & 1.39 \\
\hline $\mathbf{7 5 \%}$ & 1.79 & 1.74 & 1.70 & 1.69 & 1.68 & 1.55 & 1.47 & 1.38 & 1.14 \\
\hline
\end{tabular}

Table.2 Average log count of Rhizopus species exposed to dispersant (OSD/LT) for 28 days

\begin{tabular}{|l|l|l|l|l|r|l|l|l|c|}
\hline Conc./Duration & $\mathbf{0}$ & $\mathbf{4}$ & $\mathbf{8}$ & $\mathbf{1 2}$ & $\mathbf{2 4}($ hours) & $\mathbf{7}$ & $\mathbf{1 4}$ & $\mathbf{2 1}$ & $\mathbf{2 8}$ (Days) \\
\hline O \% & 2.24 & 2.30 & 2.31 & 2.33 & 2.35 & 2.36 & 2.36 & 2.37 & 2.38 \\
\hline $\mathbf{1 0 \%}$ & 2.22 & 2.19 & 2.17 & 2.14 & 2.11 & 2.00 & 1.94 & 1.85 & 1.76 \\
\hline $\mathbf{2 5 \%}$ & 2.20 & 2.02 & 1.99 & 1.97 & 1.92 & 1.93 & 1.90 & 1.83 & 1.70 \\
\hline $\mathbf{5 0 \%}$ & 2.11 & 1.93 & 1.88 & 1.85 & 1.81 & 1.88 & 1.81 & 1.78 & 1.64 \\
\hline $\mathbf{7 5 \%}$ & 2.02 & 1.89 & 1.81 & 1.77 & 1.73 & 1.84 & 1.73 & 1.62 & 1.48 \\
\hline
\end{tabular}


Table.3 Average log count of Aspergillus species exposed to dispersant (OSD/SEACARE) for 28 days

\begin{tabular}{|l|l|l|l|l|r|l|l|l|r|}
\hline Conc./Duration & $\mathbf{0}$ & $\mathbf{4}$ & $\mathbf{8}$ & $\mathbf{1 2}$ & $\mathbf{2 4}$ (hours) & $\mathbf{7}$ & $\mathbf{1 4}$ & $\mathbf{2 1}$ & $\mathbf{2 8}$ (days) \\
\hline $\mathbf{O} \%$ & 2.06 & 2.31 & 2.32 & 2.33 & 2.34 & 2.35 & 2.36 & 2.37 & 2.38 \\
\hline $\mathbf{1 0 \%}$ & 2.01 & 1.99 & 1.97 & 1.97 & 1.95 & 1.94 & 1.90 & 1.84 & 1.79 \\
\hline $\mathbf{2 5 \%}$ & 1.97 & 1.92 & 1.91 & 1.90 & 1.88 & 1.87 & 1.77 & 1.73 & 1.76 \\
\hline $\mathbf{5 0 \%}$ & 1.90 & 1.88 & 1.85 & 1.81 & 1.72 & 1.74 & 1.73 & 1.60 & 1.49 \\
\hline $\mathbf{7 5 \%}$ & 1.87 & 1.83 & 1.81 & 1.78 & 1.69 & 1.70 & 1.65 & 1.50 & 1.00 \\
\hline
\end{tabular}

Table.4 Average log count of Rhizopus species exposed to dispersant (OSD/SEACARE) for 28 days

\begin{tabular}{|l|l|l|l|l|l|l|l|l|l|}
\hline Conc./Duration & $\mathbf{0}$ & $\mathbf{4}$ & $\mathbf{8}$ & $\mathbf{1 2}$ & $\mathbf{2 4}$ & $\mathbf{1 6 8}$ & $\mathbf{3 3 6}$ & $\mathbf{5 0 4}$ & $\mathbf{6 7 2}($ Hrs) \\
\hline $\mathbf{O \%}$ & 2.23 & 2.30 & 2.32 & 2.33 & 2.34 & 2.23 & 2.30 & 2.32 & 2.33 \\
\hline $\mathbf{1 0 \%}$ & 2.18 & 2.17 & 2.17 & 2.13 & 2.06 & 2.18 & 2.17 & 2.17 & 2.13 \\
\hline $\mathbf{2 5 \%}$ & 2.11 & 2.10 & 2.09 & 2.07 & 2.00 & 2.11 & 2.10 & 2.09 & 2.07 \\
\hline $\mathbf{5 0 \%}$ & 2.01 & 1.92 & 1.90 & 1.87 & 1.80 & 2.01 & 1.92 & 1.90 & 1.87 \\
\hline $\mathbf{7 5 \%}$ & 1.80 & 1.79 & 1.78 & 1.77 & 1.69 & 1.80 & 1.79 & 1.78 & 1.77 \\
\hline
\end{tabular}

Table.5 Median lethal concentration (LC50) of dispersant (OSD/SEACARE) from percentage mortality of Aspergillus sp. in Freshwater

\begin{tabular}{|c|c|c|c|c|}
\hline Concentration (\%) & $\%$ mortality & Mean \% mortality & $\begin{array}{l}\text { Conc. } \\
\text { Different }\end{array}$ & $\begin{array}{l}\sum \text { of Conc. diff. } \times \\
\text { mean } \% \text { mortality }\end{array}$ \\
\hline O & 0 & & & \\
\hline 10 & 100.16 & 16.69 & 10 & 166.93 \\
\hline 25 & 122.07 & 20.35 & 15 & 305.18 \\
\hline 50 & 156.3 & 26.05 & 25 & 621.25 \\
\hline \multirow[t]{2}{*}{75} & 189.99 & 31.67 & 25 & 791.63 \\
\hline & & & & $\sum=1884.99$ \\
\hline \multicolumn{5}{|c|}{$\begin{array}{l}\text { LC }_{50}=\text { LC }_{100}-\sum \text { CONC. DIFF. } \times \text { MEAN \% MORTALITY } \\
\text { LC50 }=75-\frac{1884.99}{100} \\
\text { LC50 }=75-18.85 \\
\text { LC50 }=56.15 \%\end{array}$} \\
\hline
\end{tabular}


Table.6 Median lethal concentration (LC50) of dispersant (OSD/SEACARE) from percentage mortality of Rhizopus $s p$

\begin{tabular}{|c|c|c|c|c|}
\hline Concentration (\%) & $\%$ mortality & Mean \% mortality & Conc. different & $\begin{array}{l}\sum \text { of Conc. diff. } \times \\
\text { mean } \% \text { mortality }\end{array}$ \\
\hline $0 \%$ & o & 0 & 0 & 0 \\
\hline $10 \%$ & 89.66 & 14.94 & 10 & 149.43 \\
\hline $25 \%$ & 115.87 & 19.31 & 15 & 289.68 \\
\hline $50 \%$ & 149.35 & 24.89 & 25 & 622.29 \\
\hline $75 \%$ & 152.15 & 25.36 & 25 & 633.96 \\
\hline & & & & $\sum 1695.36$ \\
\hline $\begin{array}{rl}\mathbf{L C}_{50}=\mathbf{L C}_{100}-\sum \mathbf{C C} & \mathbf{1 0 0} \\
\mathbf{L C 5 0}= & \mathbf{7 5}-\mathbf{1 6 9 5 . 3} \\
& 100 \\
\mathbf{L C 5 0}= & \mathbf{7 5}-\mathbf{1 6 . 9 5} \\
\mathbf{L C 5 0}= & \mathbf{5 8 . 0 5 \%}\end{array}$ & $\frac{\text { NC. DIFF. } \times \text { N }}{\% \text { CONT }}$ & $\frac{\text { AN \% MORTALIT }}{\text { LL }}$ & & \\
\hline
\end{tabular}

Table.7 Median lethal concentration (LC50) of dispersant (OSD/LT) from percentage mortality of Rhizopus sp.

\begin{tabular}{|c|c|c|c|c|}
\hline Concentration (\%) & $\%$ mortality & Mean \% mortality & Conc. Different & $\begin{array}{l}\sum \text { of Conc. diff. } \times \\
\text { mean } \% \text { mortality }\end{array}$ \\
\hline $0 \%$ & 0 & 0 & 0 & \\
\hline $10 \%$ & 92.16 & 15.36 & 10 & 153.6 \\
\hline $25 \%$ & 109.06 & 18.18 & 15 & 272.65 \\
\hline $50 \%$ & 123.63 & 20.61 & 25 & 515.13 \\
\hline \multirow[t]{2}{*}{$75 \%$} & 172.58 & 28.76 & 25 & 719.08 \\
\hline & & & & $\sum 1660.46$ \\
\hline $\begin{aligned} \mathbf{L C}_{50} & =\mathbf{L C}_{100}-\sum \mathbf{C C} \\
\mathbf{L C 5 0} & =\mathbf{7 5}-\frac{\mathbf{1 6 6 0 . 4}}{100} \\
\mathbf{L C 5 0} & =\mathbf{7 5}-16.60 \\
\mathbf{L C 5 0} & =\mathbf{5 8 . 4 0 \%}\end{aligned}$ & $\frac{\text { NC. DIFF. } \times \text { I }}{\% \text { CONT }}$ & \% MORTALITY & & \\
\hline
\end{tabular}


Table.8 Median lethal concentration (LC50) of dispersant (OSD/LT) from percentage mortality of Aspergillus sp

\begin{tabular}{|c|c|c|c|c|}
\hline Concentration (\%) & $\%$ mortality & Mean \% mortality & Conc. different & $\begin{array}{l}\sum \text { of Conc. diff. } \times \\
\text { mean } \% \text { mortality }\end{array}$ \\
\hline $0 \%$ & 0 & & 0 & \\
\hline $10 \%$ & 87.25 & 14.54 & 10 & 145.4 \\
\hline $25 \%$ & 117.22 & 19.54 & 15 & 293.05 \\
\hline $50 \%$ & 146.34 & 24.39 & 25 & 609.75 \\
\hline $75 \%$ & 161.03 & 26.84 & 25 & 670.96 \\
\hline & & & & $\sum 1719.16$ \\
\hline \multicolumn{5}{|c|}{$\begin{aligned} \text { LC }_{50} & =\mathrm{LC}_{100}-\sum \text { CONC. DIFF. } \times \text { MEAN \% MORTALITY } \\
\text { LC50 } & =75-\frac{1719.16}{100} \\
\text { LC50 } & =75-17.19 \\
\text { LC50 } & =58.81 \%\end{aligned}$} \\
\hline
\end{tabular}

Figure.1 Microbial counts from the freshwater

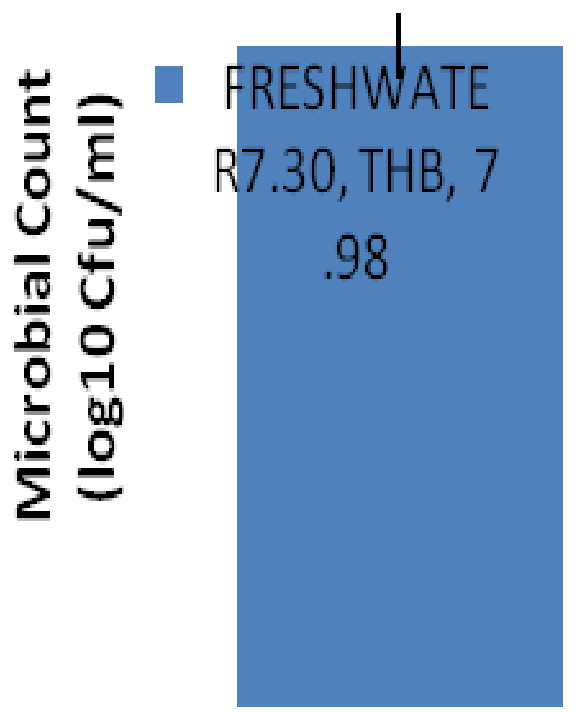

Microbial type

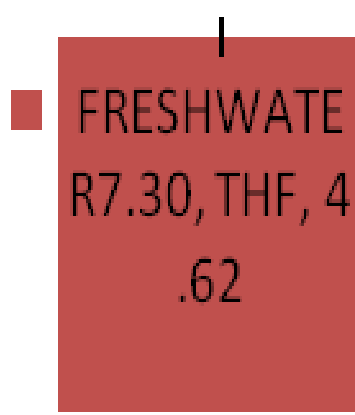

Key: THB= Total Heterotrophic Bacteria, THF $=$ Total HeterotrophicFungi 
Figures showing percentage survival of both species used in this study (Aspergillus and Rhizopus species) exposed to toxicants with different concentrations

Figure.2 Percentage survival of dispersant (OSD/SEACARE) on Aspergillus species in freshwater

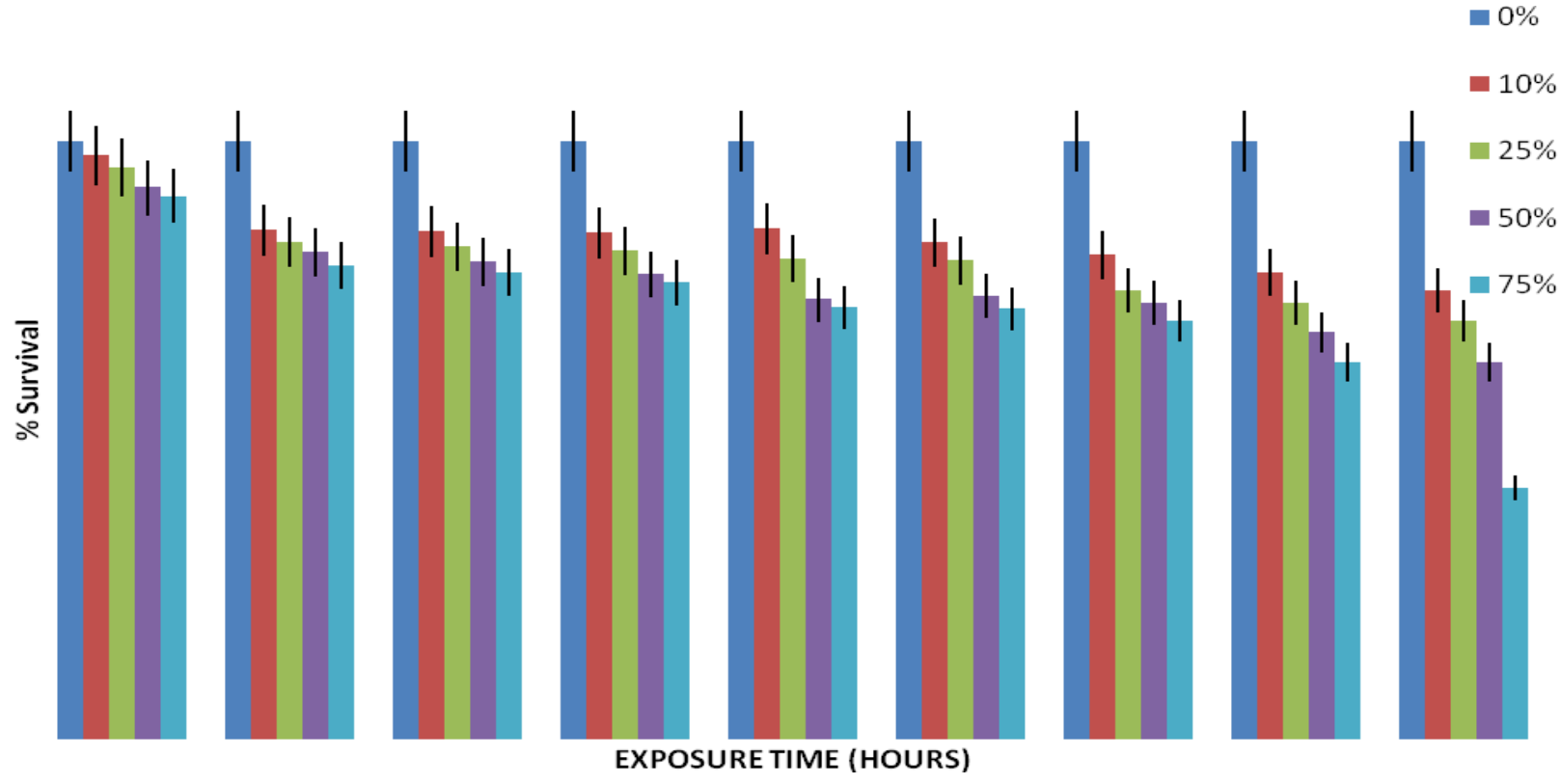

Figure.3 Percentage survival of dispersant (OSD/SEACARE) on Rhizopus species in freshwater

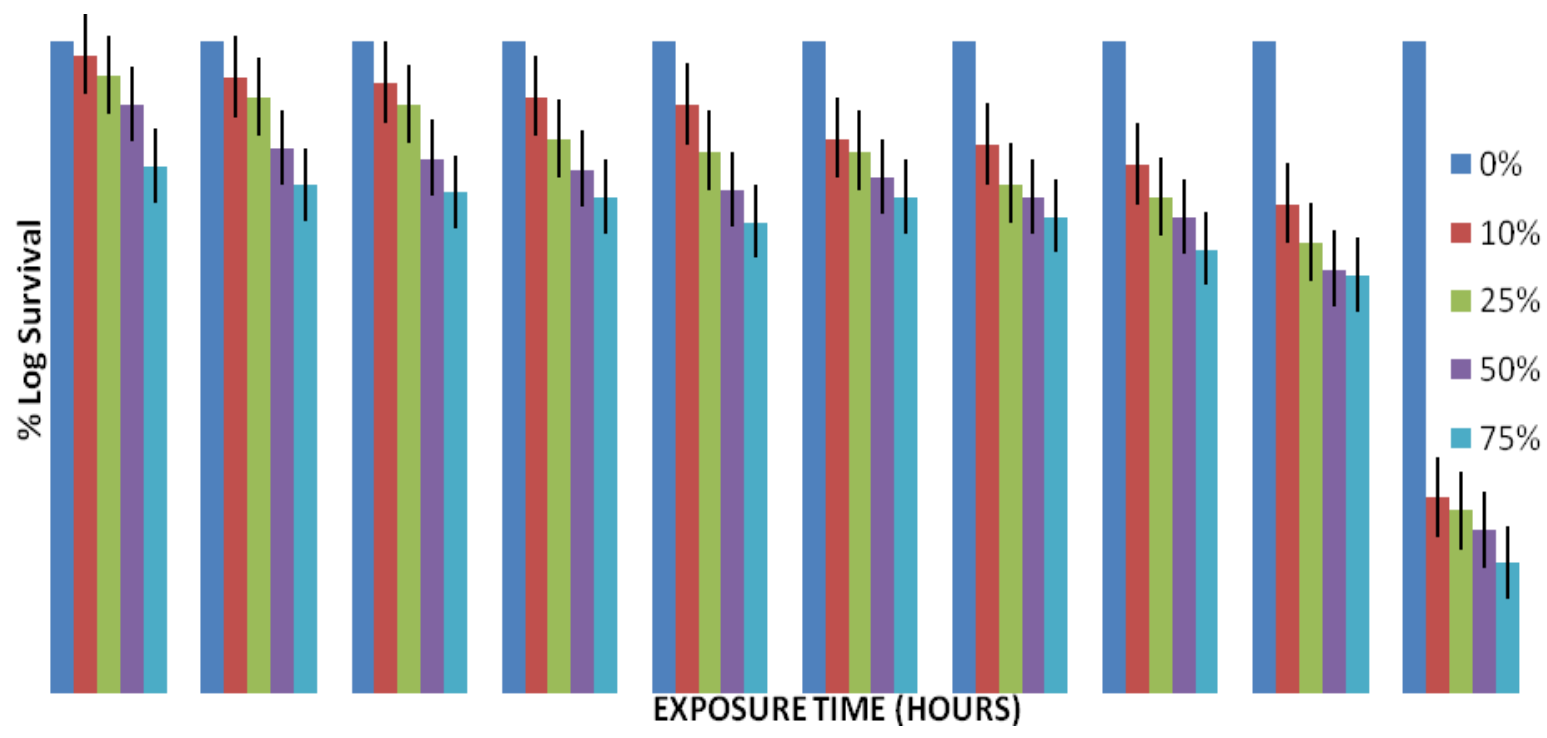


Figure.4 Percentage survival dispersant (OSD/LT) on Rhizopus species in freshwater

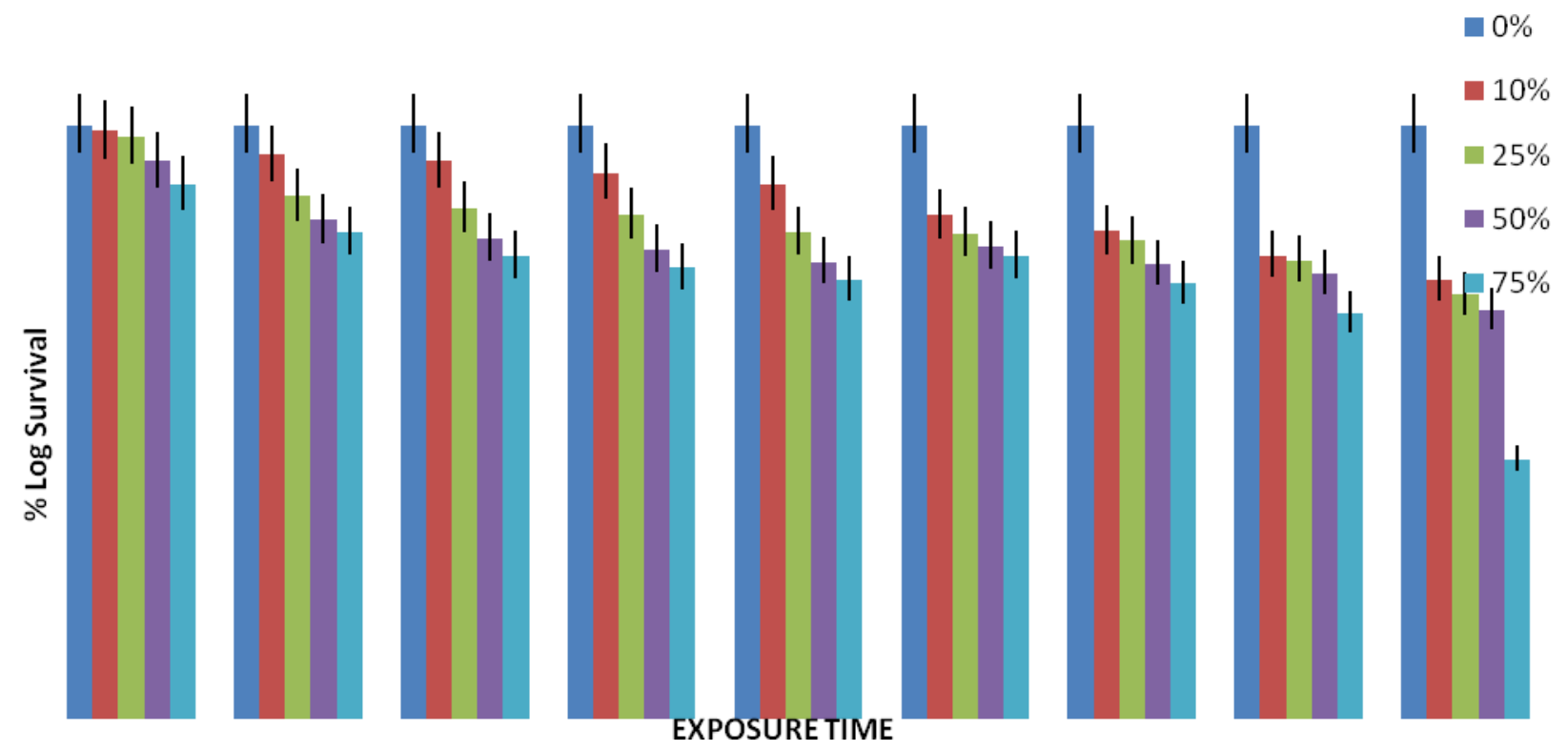

Conclusion and recommendation are as follows:

The result obtained showed that the two dispersants employed in this study pose lethal threats to the biological population of the aquatic environment and tends to seriously alter the overall stability of the river ecosystem as observed with the response of Aspergillus and Rhizopus species to the toxicity of dispersants with respect to other forms of life. The study revealed that the fungal species; Aspergillus and Rhizopus species responded differently to different concentrations of the two toxicants from time to time and the response of the organisms due to the presence of the toxicant may alter or affect the process of decomposition, mineralization and nutrient generation which will in turn disturb the nature of the ecosystem and biogeochemical cycle.

Furthermore, the study also revealed that dispersants contain some chemical components that can be very hazardous to life, reducing productivity and promoting death of not just the aquatic forms of life (both the micro and macro flora) but also higher forms of life such as humans and other mammals that make use of the lower forms as source of food and other means of survival.

Therefore, it is recommended that the use of dispersants that are less toxic to the environment should be encouraged prior to the production of third generation dispersants.

\section{References}

Bennett, J. W. (2010). An overview of the genus Aspergillus. In: Machida, m. and Gomi, K., Eds., Aspergillus: Molecular Biology and Genomics.

Cheesbrough, M. (2006). District Laboratory practice in tropical countries, part 2 , second edition, Cambridge University Press. New York.

Fingas, M., Fieldhouse, B., Mullin, J. (1995). Water in-oil emulsions. How they are formed and how they broken. In: Proceeding of the 1995 International oil spill conference. Long Beach, California Pp. 829-830.

Hamdan, L. J. Fulmer, P.A. (2011) Effects of 
corexit EC9500 on bacteria from a beach oiled by the deepwater horizon spill. Aquatic. Microbiology. Ecology. 63:101-109.

National Research council (NRC) (2005). Oil spill dispersants. The national academic press, Washington, DC, USA.

Odokuma, L.O. and Okpokwasili. G.C, (1992). Role of Composition in the degradability of oil spill dispersants Waste Management, 12, 39-43.

Okerentugba, E.U. and Ezeronye, A.O (2003). Studies on the effect of abattoir and industrial effluents on the heavy metals and microbial quality of Aba River Nigeria. African Journal of Biotechnology, 4(3), 266-272.

Prescott, L.M., Harley, J.P. and Klein, D.A.
(2005). Microbiology. 6th ed. McGraw Hill,

Williams, J. O. and Dilosi. L. B. (2018) Response of Chemolithotrophic Nitrobacter, Nitrosomonas to Toxicity of Organophoshphate and Pyrethroid Pesticides, Asian Journal of Biology, 7(1): 1-8,

Williams, J. O. and Dimbu, P. U. (2015), Effect of abattoir waste water on soil microbial communities. Scholars Academic Journals of Bioscience. 3(5): 452-455

Williams, J.O., Ogolo, C.N. Response of Aspergillus Species to the Toxicity of domestic detergent's. Nigeria Journal of Microbiology. 208; 32(1): 43344343.

\section{How to cite this article:}

Williams, Janet Olufunmilayo, Chibuike, Princess Mebom and Giadom, Barinaale Happiness. 2020. Response of Aspergillus and Rhizopus species to the Toxicity of Dispersants. Int.J.Curr.Microbiol.App.Sci. 9(01): 2487-2496. doi: https://doi.org/10.20546/ijcmas.2020.901.283 